\title{
Visualizing Resistance: Foucauldian Ethics and the Female Body Builder
}

\author{
Megan A. Dean
}

In "Foucault Pumped: Body Politics and the Muscled Woman," Honi Fern Haber argues that because patriarchy reduces women to mere bodies, feminists can and should use their bodies to strategically oppose patriarchy. Drawing on a Foucauldian understanding of the relation between power and aesthetics, Haber claims that by making women's bodies visually subversive and empowering, body building is a practice of feminist resistance. This essay will begin with a discussion of Haber's paper followed by a critique based on a Foucauldian conception of ethics. While I do think that body building can be a practice of feminist resistance, I will argue that Haber's insistence on the visibility of embodied resistance is flawed. Without sufficient consideration of the non-visible aspects of normalization, namely pleasure and pain, Haber reinscribes her muscled woman into yet another normalizing scheme.

I offer this critique as part of a larger Foucauldian feminist project to elucidate potential strategies for resistance to normalizing power. In the conclusion to her book SelfTransformations, Cressida Heyes notes the importance of "making useful forms of counterattack against corporeal normalization more publicly visible and intelligible" (136). I commend Haber for attempting to do this, but I also recognize the need to be critical of such recommendations to avoid the spread of normalization in the name of resistance. In order to make a positive contribution to this project, I will end this paper with what I see as a less "dangerous" approach 
to recommending women's weight lifting as counterattack. I put forward a slightly modified version of Wendy Burns-Ardolino's proposition that women actively engage their bodies as capacities to combat patriarchal objectification of the female body. To this end, weight lifting might be recommended as a practice of feminist resistance, not for the visibly "revolting" body it may create, but as a pleasurable non-normalizing practice that cultivates experiences of the body as capacity instead of as an object.

\section{Haber's Revolting Bodies}

At the beginning of her paper, Haber declares that the goal of her project is to overthrow the patriarchy, and more particularly, the tyranny of phallocentric desire (137). As a means to this end, she advocates the presentation of bodies that problematize the reading of woman as the object of phallocentric desire. Haber believes that women are severely limited by this reading of their body, particularly in ways that prevent them from effectively resisting patriarchy, or from even wanting to resist it (142). Through the proliferation of visually disruptive bodies, Haber hopes to overcome these limitations and create space in which women are seen, and can see themselves, as more than "tits and ass" (138).

Haber uses Michel Foucault's work on power to underpin her view of the body as political battleground. She explains that for Foucault, bodies are the material upon which "rules, hierarchies, and metaphysical commitments of a culture are inscribed and reinforced" (138). This means that the workings of power can be read off the bodies it touches. The ways bodies move, dress, interact, and take up space can be interpreted as signs of power, though this power reaches much deeper than the body's surface: it also creates, develops, and reinforces identities. Haber writes, "something as mundane as the fact that men sit with their legs spread wide apart, while a 
woman is trained to cross her legs and sit tucked into herself, can...be read as shaping the meaning of male and female subjectivities" (139).

This "writing" of power on the body presents an opportunity to use aesthetics to resist certain strategies of power. Aesthetic values, which function through pleasure and desire, are constructed within, and serve to reinforce, power structures (Haber 139). Power can therefore be challenged via the rejection or contestation of aesthetic values. As phallocentric power is written directly on the female body (in the form of body shaping, clothing, makeup, shaving, etc.), Haber suggests that women can weaken this power through the refusal to "reproduce" it by conforming to its aesthetic norms. Writing something different on the female body will challenge the "everyday male readings" of women's bodies that reinforce phallocentric restrictions on women (Haber 142). Therefore, the cultivation of a body in contravention of phallocentric aesthetic values is both a feminist and Foucauldian act of resistance: "[it] is not merely an aesthetic battle over imagery, it is also a political battle" (Haber 141).

Haber recommends the body of the female body builder as such a resistant aesthetic. She claims that the combination of traditionally masculine strength and the female body can be both subversive and empowering for women. ${ }^{1}$ The muscled woman problematizes phallocentric readings of women by challenging interpretations of weakness, timidity, or inferiority, and thus undermines the "inevitability of sexual domination" (Haber 145; 142). The female body builder's body also calls into question the naturalness of stereotypical feminine traits, such as submissiveness, delicacy, and weakness, and, in doing so, undermines the idea that there are natures at all (Haber 145). In these ways, writes Haber, the muscled woman forces a rethinking of the meaning of women's bodies; by combining femininity and strength, images traditionally kept separate, female muscle will "expand our language, will present us with new metaphors, 
that like all good metaphors, will reshape our ways of seeing" (153). Haber hopes this "revisioning" will do more than force unconventional readings of women's bodies: it should open up new, non-phallocentric ways of understanding ourselves and each other (154).

In order to play this resistant role, the muscled woman's body must be "immediately and obviously_even shockingly_present" (Haber 142). This means huge muscles; the "revolting" aspects of the muscled woman's body must be inscribed in plain sight in order to force the necessary re-readings. For this reason, the bodies of other female athletes will not suffice, for although these women may be physically strong and feel empowered, "such internal feelings do not problematise seeing, and the need for such problematising is my thesis, the achievement of such, my goal" (Haber 143). These women's bodies are too easily read as normal, even attractive, by phallocentric standards. ${ }^{2}$

While she finds the image of the female body builder very promising, Haber admits that getting "pumped" is not a straightforward solution to the problem of phallocentric power. Foucault writes that resistance comes from within power, and Haber understands this as a threat. Haber warns that the dangers of co-optation and collusion are always present, and thus muscled women must be alert for the "power [which] is always lurking on the other side of resistance" (Haber 153). ${ }^{3}$ The muscled woman's body will be interpreted within the structures of power, “at the mercy of readings (and subject to misreadings)," and her body's resistant value may be lost in translation (Haber 146). Female muscle may be sold as the key to health, or her body will be read as an attempt to be more manly, reinforcing masculine superiority (Haber 152). On the other hand, if the concept of femininity expands to include muscle, the muscled woman is also disempowered: this expansion "defuses the radical import of the image by making it one more 
possibility for that which arouses phallocentric desire" (Haber 152). If the "male gaze" can read the muscled woman's body as attractive or feminine, then her resistance has failed. ${ }^{4}$

Haber is also concerned that women will not find their subversive muscles empowering due to the influence of normalized desires. Haber writes, "women are not just subjected to these [normalized phallocentric] desires; they also constitute themselves as subjects defined by such desires" (141). ${ }^{5}$ Power is not only oppressive but constructive; it creates subjectivities, identities, pleasures, and desires. Through the production of normalized (i.e., phallocentric) desires, power makes women "come to desire the very same things that limit our life choices" (Haber 140). Drawing on the work of Sandra Bartky, Haber notes that many women's self-worth is premised on male approval; for some women, this includes the need to feel desired by men (147). Bodybuilder and feminist scholar Leslie Heywood describes this sentiment, noting female body builder's anxiety and fear over the "loss of approval, acceptance and love that acceding to the norm brings them" (Heywood, Bodymakers 33). Furthermore, since the muscled woman's body puts the normalized femininity into question, Haber's shocking aesthetics may threaten women's identities as fundamentally sexed beings. Preserving and cultivating this fundamentally feminine sense of self motivates the normalized bodies Haber wants women to reject.

Haber complains that "many women, even those who may seem to be the embodiment of radical possibilities, do not want to be liberated from phallocentric desire" (149). While these women's bodies may not conform to phallocentric ideals, the hope of being desirable by phallocentric criteria is not easily abandoned. The connection of power and identity explains why many women are not interested in fighting patriarchal power: "women act in collusion with patriarchal power because they are constituted within discourses that give 'woman' meaning as subjects of the male gaze" (Haber 141). 
Thus the rejection of the normalized feminine body through the construction of a "revolting" one may require a radical reconstruction of (feminine) self-identity, an understandably daunting task, even for those with pressing political agendas. For these reasons, even those women who choose a muscled body for feminist reasons may find it hard to overcome normalized desires. Haber notes that breasts are often central to women's sense of self-worth. She asks,

what happens to the self-esteem of the female bodybuilder whose breasts' size shrinks significantly when she loses body fat, or whose breasts develop stretch marks from doing flies?... what if she does mind, and minds so much that she comes to hate herself (her body)? In such an instance even if her body is subversive, it will not be liberating. (Haber $156)^{6}$

It seems that even with the best feminist intentions there is a worrying conflict between presenting a subversive aesthetic and being empowered by it. Haber admits that this means the resistance she advocates is problematic: "it becomes very difficult to imagine where a chosen, and phenomenologically empowering, self-conscious resistance would come from, or why it would occur" (148). In the face of this difficulty, Haber simply reiterates that normalized desires are bad for women: "we must not minimize the threat that present desire poses to the lives of all women" (151). Therefore, these desires, and the normalized bodies they produce, should be rejected. Haber suggests that if women find the results of muscled resistance too painful, they should choose another form of bodily protest (Haber 156).

I do not find this solution (if it is meant to be one) satisfying. If our values and selfconceptions are indeed caught up in patriarchy and phallocentric desire, then I agree that we must challenge them and risk doing something others might find disturbing. Nevertheless, if Haber aims to overcome phallocentric restrictions on women's bodies and identities through aesthetics, instituting new requirements to be as "revolting" as possible seems reactionary and 
ineffective. This merely institutes a new set of restrictions, requiring constant revision to accommodate the shifting values of phallocentric aesthetics, and necessitating an ever more shocking body to remain subversive. Furthermore, by Haber's criteria it is impossible to be empowered by your own subversive body unless you can overcome your own normalized desires being challenged by your resistance. Yet, Haber does not provide guidelines for how to do this, leaving us with bodies that are, indeed, subversive but not empowering.

I believe that Haber runs into these problems because she focuses on resistance as a purely visual phenomenon. She lacks a sufficient account of the embodied experience of the resisting individual, in particular, the ways in which non-visible normalized limits are created and enforced through pleasure and pain. In the next section I will expand on this critique with a discussion of feminist and Foucauldian resistance as an aesthetics that involves much more than the visible presentation of the body.

\section{Not Just Bodies, but Pleasures}

Like Haber, there are other scholars who use Foucault's work to argue that power can be resisted with the body, and who outline strategies for active resistance to normalization. ${ }^{7}$ These $^{2}$ scholars, including Ladelle McWhorter, Cressida Heyes, Pirkko Markula and Richard Pringle, tend to draw from Foucault's later works, especially his work on ethics. A brief outline of Foucault's account of ethics will thus be helpful here.

According to Foucault, ethics can be understood as the actions or practices of the self on the self with the aim of making, developing, or transforming the self to reach a particular state of being ("The Ethics of the Concern of the Self" 291). In other words, ethics involves the relationship of the self with the self and the activities which create and develop identities 
(Foucault, "On the Genealogy" 263). Understood in this manner, ethics is not a certain set of rules but rather consists of practices of self-transformation, which may or may not be in relation to moral codes. Foucault describes these practices as technologies of the self, the activities which individuals undertake "on their own bodies and souls, thoughts, conduct, and way of being, so as to transform themselves in order to attain a certain state of happiness, purity, wisdom, perfection, or immortality" ("Technologies of the Self" 225). While we may still understand the body as inscribed by power, and identities and desires as a product of power, this power is exercised, at least in part, by the self on the self through the practice of ethics.

Weight loss programs, beauty techniques, and the other "phallocentric" aesthetic practices Haber critiques can be understood as technologies of the self, though they are subject to normalization. ${ }^{8}$ As normalizing practices, they create and reinforce subjectivities or identities to which individuals must conform (Heyes 118). This is precisely Haber's complaint about normalizing phallocentric power; there are a very limited number of ways in which a woman can be attractive by phallocentric standards, but all women are expected to work toward this telos and are judged according to their deviation from it. A woman knows that "whatever else she may become, she is importantly a body designed to please or to excite" (Bartky 81). ${ }^{9}$ As Haber argues, the practices (i.e., ethical activities) undertaken toward this telos contribute to the construction of women's bodies and identities as objects of the phallocentric gaze.

Though technologies of the self can be normalizing, Foucault suggests that ethics can also be a means of resisting or opposing normalization. Instead of requiring individuals to conform to some restrictive normative identity or subjectivity, ethics as resistance will be based on freedom. For Foucault, freedom is a fundamental correlate to power. Power relations necessarily allow for the possibility to alter and modify these relations, in other words, to resist 
certain moves or tactics of power through the strategic utilization of power (Foucault, "End of the Monarchy of Sex" 224). ${ }^{10}$ The capacity to negotiate power relations in ways that might change those relations is freedom. As Jana Sawicki notes, this capacity importantly includes the ability to question and challenge received identities and values (101). ${ }^{11}$

Where there is no freedom, there is no power-only domination (Foucault, "The Ethics of the Concern of the Self" 283). Domination occurs when power relations are rigid, asymmetrical, and extremely restrictive of actions and possibilities. This precludes manoeuvres that might open up power relations and allow for freedom. Foucault gives the example of $18^{\text {th }}$ and $19^{\text {th }}$ century housewives as dominated by the conventional marital structure of the time (“The Ethics of the Concern of the Self" 292). The housewives' only options for action were not sufficient to reverse or alter the power relations that restricted them. As "the conscious [réfléchie] practice of freedom," an ethics of resistance should avoid the proliferation and reinforcement of domination, and learn to use technologies of the self in ways "that will allow us to play these games of power with as little domination as possible" (Foucault, "The Ethics of the Concern of the Self" 284; 298).

Foucault scholar Dianna Taylor explains that those interested in ethics as resistance should "engage in self-discipline [technologies of the self] in such a way that not only are power relations kept mobile, but new modes of existence are also made possible" (266). Recall that for Foucault, subjectivities, identities, or ways of being — in other words, the self — are not necessary, static, or innate, but are constituted, developed, and maintained through the workings of power, including technologies of the self. In order to resist normalization and its restrictions on modes of existence, the identities and values normalization presents as essential, and in relation to which our selves have been constituted, must be put into question. This questioning or 
"problematisation" of normalized identities is necessary to take up non-normalizing technologies of the self (Markula and Pringle 145). Through the practice of non-normalizing technologies of the self, we can attempt to cultivate new selves, new identities, new ways of being that are not restricted by normalization. In other words, ethics as a practice of freedom suggests that we may resist the normalized identities and bodies we have been given and take up our own existence as a work of art.

Foucauldian ethics can be understood as an aesthetics of existence. This is a consequence of Foucault's conception of the self as constructed, developed, modified by power (including technologies of the self) and the possibility to exercise this power over ourselves through ethics. Scholar Sylvia Pritsch describes this self as "a space of styling" (122). Style is simply the thoughtful practice of ethics as a self-forming activity. As artists of our own lives, we can use the tools provided to us by our cultures and societies to modify, create, and develop our capacities, strengths, and identities. ${ }^{12}$ It is important to note that this self-styling is not about applying current aesthetic values to one's life. Making a "beautiful life" by contemporary Western standards would hardly escape normalization. Rather, understanding the self as a work of art emphasises creativity and freedom in the cultivation of one's ways of being. It also necessitates a constant critical attitude toward one's own work, which may lead to the use of "diverse practices" (Markula and Pringle 141-142), and a focus on the process of making art rather than on the product. McWhorter writes, "art, in its living and working out, is not about accomplishment. It is about energy and time and discipline and self-criticism and pursuit and letting go. Art is not about being. It is about becoming" (Bodies and Pleasures 227).

Let us now bring this Foucauldian ethics to bear on Haber's suggestions. Foucault identified four aspects of technologies of the self, which we may use to analyse Haber's project 
as a potential ethical activity. The first aspect is the ethical substance, or the part of the self which is ethically or morally relevant (Foucault, "On the Genealogy" 263). For Haber, the ethical substance in question is the female body, and more generally, feminine identity. The second aspect is the mode of subjection, or the reasons or justification to engage in ethical projects (Foucault, “On the Genealogy” 264). Haber provides feminist justification: she wishes to overthrow the patriarchy, and more specifically, disrupt the phallocentric desire that limits women's aesthetic self-presentations and their identities. The next aspect is ethical work, "selfforming activity," or the means of transforming the self into an ethical subject (Foucault, "On the Genealogy" 265). Haber points to body building; it is through body building that the feminist subject becomes ethical (i.e., resistant to phallocentric norms). The final aspect is the telos, or goal-the type of individual toward which the ethical practice aims (Foucault, "On the Genealogy" 265).

Haber's telos worries me. The aim of Haber's project is, in broad terms, to liberate women from the limitations of phallocentric desire and patriarchal power. More specifically, the goal is to embody an image that is both subversive of phallocentric power, via the radicality of imagery, and empowered. ${ }^{13}$ The female body must be made into an image so radical that it is in visible opposition to, or contravention of, the normative standards of female attractiveness. Haber insists on this radicality precisely to avoid, if at all possible, its reabsorption or "translation" back into normative phallocentric power. There are at least two flaws in this strategy.

McWhorter and Heyes caution that resistance to normalization cannot simply posit "better" identities as the telos of ethical practices: "resistance to these [normalized] constraints ... cannot simply invoke alternative substantive accounts of the kinds of subjects we would be 
better off being, since these accounts will have their own apparatus of normalization" (Heyes 118). Any supposed resistance invoking a new and improved self as telos creates a normalizing force. The new ideal must be strived for, individuals will be measured against it, and once again ways of being are limited. It seems this is precisely what Haber is doing. By insisting that women's bodies are better off "radical" or "revolting" in reference to the phallocentric ideal, Haber is positing a new normative ideal. One could argue that Haber might not be concerned with new normalizing schemas, so long as they are not phallocentric or patriarchal ones. Nonetheless, Haber claims to be worried about the limitations on women's possibilities, which all normalizing schemas necessarily create.

While Haber does not advocate that all women take up the muscled body, her criteria for being "revolting" would seem to stand no matter what kind of bodily resistance is chosen. She suggests other types of bodies might also participate in aesthetic resistance to patriarchy: "bodies practicing homosexual or lesbian revolts, flagrantly tattooed bodies, flagrantly ambiguous bodies, wrinkled bodies, bodies that take up space, bodies that refuse to wear prostheses, surgically constructed bodies" (Haber 154). ${ }^{14}$ These bodies are also subject to evaluation according to some radical ideal. One wonders how radical is radical enough. ${ }^{15}$ How tattooed is tattooed enough? How "flagrantly ambiguous"?

To avoid creating new normalizing schemes in the name of resistance, McWhorter and Heyes both suggest that increases in capacity gained through disciplinary practices be separated from the increase in docility, or "the narrowing of behavioural possibility," which usually accompanies it (McWhorter, Bodies and Pleasures 180). Ethical practices cannot have a telos other than "the expansion of behavioural options" and cannot close off future possibilities for transformation (McWhorter, Bodies and Pleasures 182). McWhorter insists these practices 
maintain a structural "openness to becoming," the perpetually critical attitude of the artist, through the rejection of static goals (Bodies and Pleasures 193). Lest Haber force her resisting women into new normalizing schemes, she must abandon the radical body as telos.

Abandoning a normative telos requires a revaluation of ethical work. If the practice of body building is no longer taken up as a means to create a revolting body, what is its meaning? Normalizing practices, and the capacities they produce, are only valuable insofar as they are the means of conforming to or working toward their normative ideals. For example, Heyes looks at the various capacities created by the Weight Watchers program-enjoying fresh vegetables, having more energy to pursue hobbies and play with grandchildren-which are only valuable as a means to achieve thinness (79). The ability to enjoy raw carrots is useless if it does not make one thin. By positing the visibly radical muscled woman as her telos, Haber has devalued the practice of body building in a similar manner. The practice itself, and capacities created by itlifting progressively heavier weights, adhering to strict dietary rules, carrying groceries on one's own, feeling less physically intimidated by others - are of no value to Haber's resistant project. It is only as means or side effects of the muscled woman's "revolting" body that these phenomena have importance. Recall Haber's rejection of female athletes as potentially resistant: it is based solely on the criteria of visible non-conformity or rejection of the phallocentric ideal. The embodied activity or experiences of these women are inconsequential. Haber explicitly states that she is interested only in seeing, and dismisses the importance of "internal feelings" to her project (143).

Despite Haber's dismissal of “internal feelings," feelings actually play an important role in normalizing power. Normalized technologies of the self are often motivated by the play of pleasure and pain. Heyes describes normalizing practices as using "cycles of pain interspersed 
with brief windows of pleasure to keep subjects dependent on their authority" (121). Pain, or the threat of pain, is a primary tool for normalizing regimes, used to force subjects into compliance with practices and norms (McWhorter, Bodies and Pleasures 179). Giving in to normalizing practices is often the only way to assuage this suffering (Heyes 121). Pleasure is the reward for success in compliance, though it does not last long. Through the internalization of normalizing power, individuals "self-police" in relation to normative ideals, noting each deviation and measuring self-worth accordingly (O’Grady 97). Bartky notes that many women spend most of their lives with a "pervasive feeling of bodily deficiency" (81). Practices like dieting and "tummy toning" seem to provide the only hope for relief, however ineffective or temporary.

Failure to conform to norms linked to identity can be especially painful, and so especially motivational. Such norms, femininity being a prime example, present themselves as integral to human well-being, and the practices toward these ends are presented as necessary. Heyes notes that such practices "also often tacitly insist on their own transcendent status outside any politics of truth, and represent themselves as essential to human flourishing" (117). It seems impossible to be happy or fulfilled without reaching these normalized goals, hence the perpetual sense of deficiency Bartky points out.

Haber recognizes the pain associated with abandoning the normalized female body"there is no denying that it is difficult and frightening to move from what we know to what has not yet existed" (151)—but does not provide substantial suggestions on how to cope. As I mentioned above, Haber advises women to find another means of resistance if the pain is too damaging to their sense of self-worth. The problem is, as Heyes notes, rejecting deeply held norms (and therefore abandoning all hope of attaining them) will almost necessarily be a painful experience of loss and fear (120). It is hard to imagine any form of bodily protest, especially by 
Haber's radical criteria, that will not be damaging to the normalized identities of women. If we are trying to reject the objectification of women's bodies by phallocentric desire, won't this necessarily involve cultivating bodies that are in contravention of normalized ideals? How will we overcome the suffering caused by non-conforming bodies (even when these bodies are intentionally cultivated)? If all these practices will be painful, then by Haber's lights, we shall have to abandon any meaningful resistance, leaving us ineffective as feminists.

McWhorter and Heyes provide an alternative to abandoning resistance. They suggest that non-normalizing practices can be taken up for the pleasure they can provide: "what if we ... simply engaged in graduated disciplinary practices for their own sake-for the pleasures they bring - rather than for some goal beyond them?" (McWhorter, Bodies and Pleasures 182). Focusing on the pleasures created by engaging in ethical practices may allow us to use the technologies of the self available to us without tying us to a normalized telos, and allowing us to maintain the openness to becoming that McWhorter and Heyes promote (McWhorter, Bodies and Pleasures 184). In other words, one can take up activities usually tied to a normalized telos, and by cultivating pleasure in that activity itself, by breaking the link between the value of the activity and its results, these activities can be practices of freedom. Through the cultivation of pleasure, even those practices begun as a means to reach a normalized goal may morph into practices of freedom: "even if there is a goal at the outset, pleasurable disciplinary practices very often subvert that goal and end up perpetuating themselves outside or beyond any relation to it" (McWhorter, Bodies and Pleasures 188). Furthermore, pleasure in non-normalizing practices provides the motivation to engage in such practices without the promise of a normative telos, and may help us overcome the pain of our "failed" bodies. Instead of restricting the pleasure we take 
in our bodies to brief moments of conformity with normalized ideals, we may cultivate nonnormative pleasure in heretofore neglected, or perhaps completely new, aspects of our bodies.

It is this attention to the non-visible aspects of normalization, namely pain and pleasure, that Haber's account lacks. In light of this oversight, Haber's worries regarding the difficulties of resistance are well founded. Encouraging women to get "pumped" without recognizing the need to establish new relationships with their bodies, ones that take pleasure in strength, size, and physical capacity, will likely be so self-destructive that the resistant project will fail. Women will have to resign their practices of resistance if they have not cultivated new pleasures to counterbalance the pain of abandoning normalized self-conceptions. While it is true that many feminists would find pleasure in undermining patriarchy, the deep connection between feminine bodily norms and identity would likely render the transformative power of such pleasure ineffectual. It seems unlikely that, without explicit attention to this aspect of normalization, the pleasures of feminist identity will effectively outweigh the pain of a failed feminine identity.

If Haber wishes to base her resistance on a Foucauldian understanding of power and the body, she must take pain and pleasure seriously. It is precisely those "internal feelings" Haber rejects that need to be considered. ${ }^{16}$ As Monique Deveaux writes, “women's 'freedom' does not simply refer to subjects' objective possibilities for maneuvering or resisting within a power dynamic but concerns whether a woman feels empowered in her specific context" (224). ${ }^{17}$ By neglecting the non-visible constraints on women's possibilities for resistance, Haber merely reinscribes her resisting women into yet another normalizing scheme. I do not think the creation of new normalizing schemes, even with the best of feminist intentions, are acceptable as part of a resistant practice that should increase possibilities for ways of being, not limit them. 
This being said, I do believe that the practice of weight lifting can be an ethical practice of resistance. In the next section I will point out one way in which weight lifting might help women cultivate a pleasurable non-normalized experience of their own bodies and be an ethical practice of resistance.

\section{The Pleasures of Heavy Lifting}

Like Haber, I am interested in challenging the objectification of the female body and identity through normalization. One way we might approach this task is to engage in embodied practices that are not about the way the body looks, rather, about what the body does. Wendy Burns-Ardolino suggests that promoting an understanding of the body as capacity should be central to feminist liberatory practice. She argues that women should "actively engage" their bodies as capacities to disrupt objectifying norms (Burns-Ardolino 43). She writes, "what is at stake here, then ... is the right to be read as a body having the capacity to act, and having that capacity take precedence over the recognition of the feminine body as object" (Burns-Ardolino 47). As I have argued above, I believe that there are serious problems with a focus on image alone. Thus, I wish to modify Burns-Ardolino's suggestion to include the right to experience one's own body as capacity and to take pleasure in it as such.

I propose that the practice of weight lifting may help cultivate an experience of one's own body as a set of capabilities instead of as a visual object, and as such, be a practice of resistance. While this is not a novel claim, in the context of proselytizing forms of resistance or counterattack, thinking about the ways to present potential practices is important. Haber's insistence on radical visibility is, as I have argued, likely to be problematic for many women. 
Therefore I suggest that a focus on weightlifting as a capacity-building practice might be more successful.

The progressive character of weight lifting makes it a good candidate for bringing attention to the body's capacities. In order to build strength, one must regularly increase the weight or number of repetitions. Often, lifters record the weight lifted at each training session in order to measure progress. Progress is generally measured by ability to lift, not greater conformity to body norms. Though some exercises focus on the development of visible body parts with relation to normative ideals (tricep kickbacks as a means to prevent "underarm jiggle"), there are many other exercises that do not have particularly visible results (deadlifts, for example). ${ }^{18}$

The weight room can be a place where experience of the body as capacity takes precedence over the body as object. Feminist weight lifter Mistress Krista writes on her fitness blog Stumptuous:

"I work out in slobby gym wear with no makeup, and I get dirty and sweaty and messy haired. My breasts are not lifted and separated; they are mashed onto my chest by my cheapo sports bra. When I forget to shave my legs I don't really care. I am in there to work hard, to lift some heavy shit, and to forget about how my body looks in favour of thinking about what my body does." ("Why Don't You Look Like a Fitness Model?" my emphasis)

Taking pleasure in the ability to "lift heavy shit" may, at least temporarily, replace the normative pleasures of looking slim or pretty, and/or the normative pain of failing to do so. ${ }^{19}$ In my own experience, for example, the pleasure of doing full push-ups has far outweighed the pain I experienced over non-conforming arms. Even women like myself, who began weight lifting as a means to conform to normative body ideals, may find that the non-normative pleasure of weightlifting can transform the practice into one of freedom. 
I am not suggesting that all weightlifting is the non-normalizing practice of freedom. As I mentioned, many women, myself included, begin weight lifting as a normative practice. A survey of female celebrities like Jessica Biel, Pink, and Kelly Ripa show that the muscled feminine physique has indeed been "co-opted" into phallocentric desire, at least to some extent. The co-optation and collusion implied on the cover of one of my weightlifting books would likely horrify Haber: "Lift like a man, look like a goddess," it promises (Schuler). Nonetheless, I do think that, when coupled with the critical and creative comportment of Foucault's artist of the self, weight lifting can be taken up as a practice of freedom and help women to create new, nonphallocentric, non-objectifying ways of being in their bodies.

In general, focusing on practices that cultivate an experience of the body as capacity allows us to widen the pool of potentially resistant practices to include those Haber rejects as insufficiently visible. ${ }^{20}$ Markula and Pringle assert that "every body shape has the potential to create a reconstructed self [i.e., a non-normalized or resistant self]," if it is the result of the thoughtful practice of ethics (171). Sports theorist Holly Brubach argues that the bodies of many female athletes, while perhaps resembling normalized bodies, are nonetheless resistant because they are not about the way they look: "their muscles, like the fashion models' slenderness, are hard-earned, but here the means is not abstinence but exertion. Though their bodies have been meticulously cultivated, their bodies aren't the point: the point is their ability to perform" (Holly Brubach in Heywood, xx). Sports like running, swimming, or martial arts and activities like pilates or yoga, where the bodies cultivated will not necessarily be visibly radical, can therefore be practices of resistance. Contrary to Haber's claims, practices that appear to "co-operate" with ideal femininity are not necessarily oppressive, and those that do not "are not necessarily 'liberating"' (Markula and Pringle 151). Foucault writes that ethical practices of freedom are 
socially and historically situated: "they are models that he finds in his culture and are proposed, suggested, imposed upon him by his culture, his society, his social group," and though they may not be pursued as practices of freedom by others, they can be taken up as such by ourselves ("On the Genealogy" 291).

Though I have suggested this focus on capacity in opposition to Haber's insistence on the visible, the reconceptualization and remaking of the female body as capacity will likely have visible results. Burns-Ardolino suggests that understanding and experiencing one's body as capacity will lead to "subversive performativity" in which this understanding is played out for others to see (43). Considering the connection between the constitution of the self and social or political practices, it seems inevitable that changes to the self will affect power more broadly: "self-transformation, then, implies social transformation because institutional and social practices constitute subjectivity" (McLaren, 230). Indeed, Foucault describes the ethical in partly visual terms: ethics is "a mode of being for the subject, along with a certain way of acting, a way visible to others" ("The Ethics of the Concern of the Self" 286, my emphasis).

This performativity may play out in small ways, not the radical or shocking displays that Haber envisioned. Markula and Pringle suggest that a woman's focus on core strength at the gym, presumably in distinction to the normative insistence on "flat abs," publicly problematizes the way the "fit feminine body" is constructed (152). I would add that it in fact problematizes the feminine body as a visual object as well. This small choice shows that this woman's body is not experienced as a mere object, or at least primarily as an object, but as a vehicle for strength and balance (not to mention a pain-free back).

McWhorter notes that the wider variety of women's bodies we encounter, whether they are actively resisting norms of femininity or are simply "failed" bodies, the less we are able to 
make generalizations or sweeping characterizations about "women" as a group (McWhorter, "Practicing practicing" 160). She understands Haber as attempting to use this strategy through the recommendation of visibly revolting bodies. Yet, without addressing women's pleasures and pains in and about their own bodies, it is difficult to see how the proliferation of non-normative body types can be recommended as empowering. Nonetheless, I do agree with the basic point: the more women we see engaging their bodies as capacities, the less we are able to view them (and ourselves) as objects to be seen. Such performances, though they may seem modest, seem to fulfill Haber's wishes in a way her muscled woman cannot; they can be both subversive and empowering.

In conclusion, I think Haber is right to point out the utility of our bodies in the fight against normalizing power. On the other hand, I believe her insistence on the visibility of embodied resistance misses the mark. By focusing on a static goal and overlooking the importance of normative pleasure and pain, Haber risks instituting a new normalizing scheme. I have suggested that weight lifting may be more successfully recommended as a practice of resistance when undertaken to increase capacities and for the pleasure of the activity itself, rather than as a means to create the revolting image of female muscle. It is obvious that visibility does have an important role for ethical resistance against normalization, particularly in the ways we connect individual resistance with others; however, I hope to have pointed out that it too can be dangerous. 


\section{Notes}

${ }^{1}$ Haber does not explicitly define empowerment. She juxtaposes the muscled woman and the anorectic, stating that the anorexic woman's body might be "subversive" but is not empowered in the way the muscled woman is. This is simply a matter of the sickness and impending death of the anorexic (Haber 143). (Haber also states that the anorectic's body functions in collusion with the patriarchy and so is not truly subversive.) This makes it seem that empowerment is merely physical. However, Haber also states that if a woman despises her muscled body, she is not empowered. Thus it seems it is a mixture of confidence and physical strength or well-being.

${ }^{2}$ Not all "shocking" images will do either. An image that is subversive but not empowering for women, such as the anorectic body, is inappropriate.

3 To combat such misreadings, Haber suggests women try to foster the creation of a new category, "making strength soft, power gentle - and also gentleness powerful, softness strong" (153). It is unclear just what aesthetic this would entail, or how women could foster the creation of a new conceptual category.

${ }^{4}$ Haber notes that the "male gaze" does not depend on the sex or gender of the subject doing the gazing; both men and women read in this manner as it is constructed by phallocentric power (142).

5 I will read Haber's phallocentric power as an example of normalizing power in general. Haber describes phallocentric power in normalizing terms, especially in reference to Foucault's genealogical work, though she does not explicitly name it as such (cf. Haber 138-142).

${ }^{6}$ Haber seems to use liberation and empowerment interchangeably here. Note that for Foucault, liberation has a very specific meaning, which Haber does not seem to be using (cf. Foucault, "An Ethics of the Concern of the Self" 282-284).

${ }^{7}$ McWhorter advocates opposition or counter-attack, rather than resistance. She thinks resistance is merely negative, "a no to domination," where opposition or counter attack includes a positive creative aspect (McWhorter, Bodies and Pleasures 191). Care of the self is just one of three lines of counter attack McWhorter suggests. I have chosen to use resistance throughout as Haber does, though I recognize it is a problematic concept. See Saba Mahmood's Politics of piety for an interesting critique of feminist conceptions of resistance.

${ }^{8}$ As these practices are normalizing, I am not certain that they can be rightfully described as ethical practices. In any case, they do present themselves as such — and may, as Heyes argues, do so to conceal their normalizing character (Heyes, 10).

9 These references to "women" are not meant to be universalizing. They refer only to those women who have been subject to the normalization in question, namely the majority of women in mainstream western society. I recognize that there are important differences effaced by these generalizations. I am unable to adequately address these in the context of this paper. For recent discussion of some of these differences see Bordo 2009 and Nasser and Malson 2009. 
10 Note that this does not exclude the use of power over others, merely an avoidance of domination. Foucault calls the connection of care of the self to the use of power over others "governmentality" ("The Ethics of the Concern of the Self" 300). McWhorter notes that the exercise of power over others, or the use of governmentality, can be an extension or indeed part of care of the self insofar as it is sometimes necessary to force others to allow one to undertake non-normalizing practices (McWhorter, Bodies and Pleasures 191). See Melina Bell's article for discussion of potential regulation changes in body building competitions in order to create space for a feminist practice of body building.

${ }^{11}$ It seems to me that this definition is included within the more general one Foucault gives, as questioning or problematization of identities and values is necessary for real change in relation to these to occur. If there is no possibility of questioning the validity of a particular identity then it is likely dominating. An example of this is the dominance of heterosexuality McWhorter describes in Bodies and Pleasures.

${ }^{12}$ Foucault reminds us that though ethics as a practice of freedom may resist normalization, it does not step outside of power. The options for ethical practice "are nevertheless not something invented by the individual himself [sic]. They are models that he finds in his culture and are proposed, suggested, imposed upon him by his culture, his society, his social group" (Foucault, "On the Genealogy" 291).

${ }^{13}$ See note 1 for discussion of Haber's concept of empowerment.

14 It is interesting that Haber does not suggest obesity as an option, as it seems just as "contravening" of phallocentric norms as huge muscles.

15 In any case, the revolting muscles Haber requires are likely unattainable for many women. Becoming hugely muscled requires a great deal of time, hard work, and dedication, not to mention available funds for gym memberships and expensive food.

16 As aesthetic values are created within power structures, Haber seems to think that if the resisting body becomes aesthetically pleasing and thus desirable to men (and to women informed by normalized desire), the resistant project has failed. She warns against this expansion of male desire as a resistance neutralizing force, asking, "is the muscled woman faced with ... acceptance of her image as another outlet for male desire (in which case she is complicitous with her own oppression)"'? (Haber 150). She also rejects the resistant potential of the professional body builder because these women's economic well-being is based on their attractiveness to judges or magazine editors which are likely influenced by phallocentric desire (Haber 149-151). It is not clear to me that desire for a wide variety of female bodies is necessarily the intensification of patriarchal power. In fact, the development of pleasures in, and desires for, all sorts of bodiesboth our own bodies and other's bodies - seems to be an exciting possibility suggested by Foucault's work. It is, however, a complicated discussion that I cannot enter into here. In addition, while Haber bemoans the fact that professional body builders must objectify themselves and rely on male desire to make a living, thereby negating their resistant potential 
(149), it is not at all evident that all objectification is bad. See Martha Nussbaum's "Objectification," for example.

${ }^{17}$ Deveaux uses this point to argue that Foucault's conception of power is useless for feminist purposes. I disagree, as I think Foucault's focus on pleasures, desires, etc. can account, at least on some level, for the "internal barriers" restricting possible modes of resistance (Deveaux 226).

${ }^{18}$ Cf. Mistress Krista, Stumptuous; Schuler, The New Rules of Lifting for Women; Reno, The EatClean Diet Workout.

${ }^{19}$ I'd like to emphasize that cultivating strength is not resistant simply because women have been normalized to be and appear weak. Rather, it is resistant because it is a cultivation of capacity in general rather than a reaction to the established norm.

${ }^{20}$ I understand capacity and capability in a very broad sense, and do not wish for this focus on capacities to come across as ableist. Thanks to several colleagues who pointed out this possibility to me. For in-depth discussion of Foucauldian theory and its relation to disability studies, see Tremain (ed.), Foucault and the government of disability.

\section{Works Cited}

Bartky, Sandra. "Foucault, Femininity, and the Modernization of Patriarchal Power." Feminism and Foucault: Paths of Resistance. Ed. Lee Quinby and Irene Diamond. Boston: Northeastern University Press, 1988. 61-86.

Bell, Melina. "Strength in Muscle and Beauty in Integrity: Building a Body for Her." Journal of the Philosophy of Sport 35 (2008): 43-62.

Bordo, Susan. "Not just 'a white girl's thing': The changing face of food and body image problems." Critical Feminist Approaches to Eating Dis/Orders. Ed. Helen Malson and Maree Burns. London; New York: Routledge, 2009. 46-60.

Burns-Ardolino, Wendy A. "Reading Woman: Displacing the Foundations of Femininity." Hypatia 18, no. 3 (2003): 42-59.

Deveaux, Monique. "Feminism and Empowerment: A Critical Reading of Foucault." Feminist Interpretations of Michel Foucault. Ed. Susan J. Hekman. University Park: The Pennsylvania State University Press, 1996. 211-238.

Foucault, Michel. "On the Genealogy of Ethics: An Overview of a Work in Progress." Ethics: subjectivity and truth. Ed. Paul Rabinow. Trans. Robert Hurley et al. New York: The New Press, 1994. 253-280. 
—. "End of the Monarchy of Sex." Foucault live: collected interviews, 1961-1984. Ed. Sylvere Lotringer. Trans. Lysa Hochroth and John Johnston. New York: Semiotext(e), 1996. 214-225.

—. "Technologies of the Self." Ethics: subjectivity and truth. Ed. Paul Rabinow. Trans. Robert Hurley et al. New York: The New Press, 1994. 223-251.

- "The Ethics of the Concern of the Self as a Practice of Freedom." Ethics: subjectivity and truth. Ed. Paul Rabinow. Trans. Robert Hurley et al. New York: The New Press, 1994. 281-301.

Haber, Honi Fern. "Foucault Pumped: Body Politics and the Muscled Woman." Feminist Interpretations of Michel Foucault. Ed. Susan J. Hekman. University Park: The Pennsylvania State University Press, 1996. 137-156.

Heyes, Cressida. Self-transformations: Foucault, ethics, and normalized bodies. New York: Oxford University Press, 2007.

Heywood, Leslie. Bodymakers: a cultural anatomy of women's bodybuilding. New Brunswick; London: Rutgers University Press, 1998.

Heywood, Leslie and Shari L. Dworkin. Built to Win: The Female Athlete as Cultural Icon. Minneapolis: University of Minnesota Press, 2003.

Ian, Marcia. "The Primitive Subject of Female Bodybuilding: Transgression and Other Postmodern Myths." differences: A Journal of Feminist Cultural Studies 12, no. 3 (2001): 69-100.

Mahmood, Saba. Politics of piety: the Islamic Revival and the feminist subject. Princeton; Oxford: Princeton University Press, 2005.

Markula, Pirkko and Richard Pringle. Foucault, sport and exercise: power, knowledge and transforming the self. London; New York: Routledge, 2006.

McLaren, Margaret A. "Foucault and Feminism: Power, Resistance, Freedom." Feminism and the Final Foucault. Eds. Dianna Taylor and Karen Vintges. Urbana: University of Illinois Press, 2004. 214-234.

McWhorter, Ladelle. Bodies and Pleasures: Foucault and the Politics of Sexual Normalization. Bloomington: Indiana University Press, 1999.

- "Practicing Practicing." Feminism and the Final Foucault. Eds. Dianna Taylor and Karen Vintges. Urbana: University of Illinois Press, 2004. 143-162. 
Mistress Krista. "Why don't You Look like a Fitness Model?" Stumptous.com. 26 December 2008. Web. 29 November 2010.

Nasser, Mervat and Helen Malson. "Beyond western dis/orders: Thinness and self-starvation in other-ed women." Critical Feminist Approaches to Eating Dis/Orders. Ed. Helen Malson and Maree Burns. London; New York: Routledge, 2009. 74-86.

Nussbaum, Martha. “Objectification.” Philosophy and Public Affairs 24, no. 4 (1995): 249-291.

O'Grady, Helen. "An Ethics of the Self." Feminism and the Final Foucault. Eds. Dianna Taylor and Karen Vintges. Urbana: University of Illinois Press, 2004. 91-117.

Reno, Tosca. The Eat-Clean Diet workout. Mississauga: Robert Kennedy Publishing, 2008.

Sawicki, Jana. Disciplining Foucault. New York: Routledge, 1991.

Schuler, Lou and Cassandra Forsythe. The New Rules of Lifting for Women: Lift like a Man, Look like a Goddess. New York: Avery, 2007.

Taylor, Dianna. "Foucault's Ethos: Guide(post) for Change" Feminism and the Final Foucault. Eds. Dianna Taylor and Karen Vintges. Urbana: University of Illinois Press, 2004. 258274.

Tremain, Shelley (ed.). Foucault and the government of disability. Michigan: University of Michigan Press, 2005. 